\title{
A Bis-Monophospholyl Dysprosium Cation Showing Magnetic Hysteresis at 48 Kelvin
}

Peter Evans, Daniel Reta, George F. S. Whitehead, Nicholas F. Chilton,* and David P. Mills*

Department of Chemistry, School of Natural Sciences, The University of Manchester, Oxford Road, Manchester, M13 9PL, U.K.

\begin{abstract}
Single-molecule magnets (SMMs) have potential applications in high-density data storage, but magnetic relaxation times at elevated temperatures must be increased to make them practically useful. Bis-cyclopentadienyl lanthanide sandwich complexes have emerged as the leading candidates for SMMs that show magnetic memory at liquid nitrogen temperatures, but the relaxation mechanisms mediated by aromatic $\mathrm{C}_{5}$ rings have not been fully established. Here we synthesise a bismonophospholyl dysprosium SMM $\left[\mathrm{Dy}(\mathrm{Dtp})_{2}\right]\left[\mathrm{Al}\left\{\mathrm{OC}\left(\mathrm{CF}_{3}\right)_{3}\right\}_{4}\right]\left(\mathbf{1}, \mathrm{Dtp}=\left\{\mathrm{P}\left(\mathrm{C}^{\mathrm{t} B u C M e}\right)_{2}\right\}\right)$ by the treatment of in situ-prepared "[Dy(Dtp $\left.)_{2}\left(\mathrm{C}_{3} \mathrm{H}_{5}\right)\right] "$ with $\left[\mathrm{HNEt}_{3}\right]\left[\mathrm{Al}\left\{\mathrm{OC}\left(\mathrm{CF}_{3}\right)_{3}\right\}_{4}\right] . \quad$ SQUID magnetometry reveals that $\mathbf{1}$ has an effective barrier to magnetisation reversal of $1,760 \mathrm{~K}\left(1,223 \mathrm{~cm}^{-1}\right)$ and magnetic hysteresis up to $48 \mathrm{~K}$. Ab initio calculation of the spin dynamics reveal that transitions out of the ground state are slower in $\mathbf{1}$ than in the first reported dysprosocenium SMM, $\left[\mathrm{Dy}\left(\mathrm{Cp}^{\mathrm{ttt}}\right)_{2}\right]\left[\mathrm{B}\left(\mathrm{C}_{6} \mathrm{~F}_{5}\right)_{4}\right]\left(\mathrm{Cp}^{\mathrm{ttt}}=\mathrm{C}_{5} \mathrm{H}_{2}{ }^{\mathrm{t}} \mathrm{Bu}_{3}-1,2,4\right)$, however relaxation is faster in $\mathbf{1}$ overall due to the compression of electronic energies and to vibrational modes being brought on-resonance by the chemical and structural changes introduced by the bis-Dtp framework. With the preparation and analysis of $\mathbf{1}$ we are thus able to further refine our understanding of relaxation processes operating in bis- $\mathrm{C}_{5} / \mathrm{C}_{4} \mathrm{P}$ sandwich lanthanide SMMs, which is the necessary first step towards rationally achieving higher magnetic blocking temperatures in these systems in future.
\end{abstract}




\section{Introduction}

The potential for high-density data storage devices based on single-molecule magnets (SMMs) is reliant upon increasing spin relaxation times towards practically useful timescales at relatively high temperatures, away from expensive liquid helium regimes to that of cheap and abundant liquid nitrogen. ${ }^{1}$ Lanthanide (Ln) based SMMs have been at the forefront of research in this area for the last fifteen years, ${ }^{2}$ and design principles popularised by Rinehart and Long in $2011^{3}$ directed the community towards longer relaxation times by means of massive increases in the energy barrier to magnetic reversal ( $U_{\text {eff) }}{ }^{4}$ These large increases in $U_{\text {eff }}$ did not lead to corresponding increases in magnetic remanance temperatures ${ }^{5}$ until the dysprosocenium cation $\left[\mathrm{Dy}\left(\mathrm{Cp}^{\mathrm{ttt}}\right)_{2}\right]^{+}\left(\mathrm{Cp}^{\mathrm{ttt}}=\mathrm{C}_{5} \mathrm{H}_{2} t \mathrm{Bu}_{3}-1,2,4\right)$ was shown to exhibit magnetic hysteresis at $T_{\mathrm{H}}=60 \mathrm{~K}$ in $2017 .{ }^{6} \mathrm{We}$ attributed the high temperature magnetic remanance in this bis- $\mathrm{Cp}^{\mathrm{ttt}}$ system to the combination of a $\mathrm{Dy}^{3+}$ centre with rigid, charge-dense $\pi$ aromatic rings; we also predicted that removal of $\mathrm{C}-\mathrm{H}$ groups from the $\mathrm{C}_{5}$ ring could increase hysteresis temperatures further. ${ }^{6}$ This has been proven correct, with hysteresis temperatures up to $T_{\mathrm{H}}=80 \mathrm{~K}$ observed for peralkylated bis-cyclopentadienyl Ln complexes reported in the last two years. ${ }^{7}$

An alternative strategy to remove $\mathrm{C}-\mathrm{H}$ groups from $\mathrm{C}_{5}$ frameworks is heteroatom substitution; ${ }^{8}$ indeed, the magnetic properties of theoretical $\left[\mathrm{Dy}\left(\mathrm{E}_{5}\right)_{2}\right]^{+}(\mathrm{E}=\mathrm{N}, \mathrm{P})$ cations have recently been predicted to exhibit high $U_{\text {eff }}$ values. ${ }^{9}$ Phospholyl ligands are a valid alternative to cyclopentadienyls as the $\mathrm{P}$ lone pairs are relatively soft, so they tend to exhibit $\eta^{5}$-binding modes with $\mathrm{Ln}$ ions. ${ }^{10}$ Synthetic routes towards peralkylated monophospholyls are already mature; of most relevance here, the Ln chemistry of $\left\{\mathrm{P}\left(\mathrm{C}^{\mathrm{t} B u C M e}\right)_{2}\right\}(\mathrm{Dtp})$ has already been developed. ${ }^{11}$ The straightforward synthesis of $\left[\mathrm{Dy}(\mathrm{Dtp})_{2}(\mathrm{I})\right]$ from $\mathrm{DyI}_{3}$ and two equivalents of KDtp was reported by Nief and co-workers in $2009,{ }^{11 \mathrm{~d}}$ and we envisaged that this would be an ideal starting material towards the isolation of a $\left[\mathrm{Dy}(\mathrm{Dtp})_{2}\right]^{+}$cation. Herein we report the synthesis and magnetic properties of this cation, and correlate our results with $a b$ initio calculations of the spin dynamics to probe the effects of aromatic $\mathrm{P}-\mathrm{C}$ vibrational modes in magnetic relaxation mechanisms compared to aromatic $\mathrm{C}-\mathrm{C}$ vibrations. We find that relaxation is expedited in the $\left[\mathrm{Dy}(\mathrm{Dtp})_{2}\right]^{+}$cation compared to $\left[\mathrm{Dy}\left(\mathrm{Cp}^{\mathrm{ttt}}\right)_{2}\right]^{+}$as additional vibrational modes are brought on-resonance, providing new insights into the relaxation pathways that operate in bis- $\mathrm{C}_{4} \mathrm{P}$ vs. bis- $\mathrm{C}_{5} \mathrm{Ln}$ sandwich SMMs. 


\section{Results and Discussion}

\section{Synthesis}

Treatment of "[Dy(Dtp $\left.)_{2}\left(\mathrm{C}_{3} \mathrm{H}_{5}\right)\right] "$ with $\left[\mathrm{NEt}_{3} \mathrm{H}\right]\left[\mathrm{Al}\left\{\mathrm{OC}\left(\mathrm{CF}_{3}\right)_{3}\right\}_{4}\right]$ in benzene gave $\left[\mathrm{Dy}(\mathrm{Dtp})_{2}\right]\left[\mathrm{Al}\left\{\mathrm{OC}\left(\mathrm{CF}_{3}\right)_{3}\right\}_{4}\right]$ (1) in 26\% yield following work-up and recrystallization from chlorobenzene (Scheme 1). "[Dy(Dtp $\left.)_{2}\left(\mathrm{C}_{3} \mathrm{H}_{5}\right)\right]$ ” was prepared in situ from the salt metathesis reaction of $\left[\mathrm{Dy}(\mathrm{Dtp})_{2}(\mathrm{I})\right]^{11 \mathrm{~d}}$ with $\mathrm{C}_{3} \mathrm{H}_{5} \mathrm{MgCl}$, whilst $\left[\mathrm{NEt}_{3} \mathrm{H}\right]\left[\mathrm{Al}\left\{\mathrm{OC}\left(\mathrm{CF}_{3}\right)_{3}\right\}_{4}\right]$ was isolated from the reaction of $\mathrm{Li}\left[\mathrm{Al}\left\{\mathrm{OC}\left(\mathrm{CF}_{3}\right)_{3}\right\}_{4}\right]^{12}$ with $\mathrm{NEt}_{3} \mathrm{HCl}$ by adapting procedures used for the synthesis of $\left[\mathrm{NEt}_{3} \mathrm{H}\right]\left[\mathrm{B}\left(\mathrm{C}_{6} \mathrm{~F}_{5}\right)_{4}\right] .{ }^{13}$ The triethylammonium reagent was selected as it provides an entropic driving force with dual amine and alkene elimination during the reaction, ${ }^{14}$ and the $\left[\mathrm{Al}\left\{\mathrm{OC}\left(\mathrm{CF}_{3}\right)_{3}\right\}_{4}\right]^{-}$anion is more weakly coordinating than the $\left[\mathrm{B}\left(\mathrm{C}_{6} \mathrm{~F}_{5}\right)_{4}\right]^{-}$anion, ${ }^{15}$ which has been used for the synthesis of all $\mathrm{Ln}$ metallocenium cations to date. ${ }^{6,7,16}$ The direct reaction of $\left[\mathrm{Dy}(\mathrm{Dtp})_{2}(\mathrm{I})\right]$ with $\left[\mathrm{H}\left(\mathrm{SiEt}_{3}\right)_{2}\right]\left[\mathrm{B}\left(\mathrm{C}_{6} \mathrm{~F}_{5}\right)_{4}\right]^{17}$ gave an intractable mixture of products. ${ }^{1} \mathrm{H},{ }^{13} \mathrm{C}$ and ${ }^{31} \mathrm{P}$ NMR spectra of a sample of $\mathbf{1}$ in $d_{5^{-}}$ chlorobenzene were uninformative due to paramagnetism, but the $\left[\mathrm{Al}\left\{\mathrm{OC}\left(\mathrm{CF}_{3}\right)_{3}\right\}_{4}\right]^{-}$anion was detected by ${ }^{19} \mathrm{~F}$ NMR spectroscopy $\left(\delta_{\mathrm{F}}:-90.50 \mathrm{ppm} ; v^{1 / 2}=300 \mathrm{~Hz}\right)$; the presence of paramagnetic $\left[\mathrm{Dy}(\mathrm{Dtp})_{2}\right]^{+}$ cations has broadened this signal and shifted it considerably from the $\left[\mathrm{NEt}_{3} \mathrm{H}\right]\left[\mathrm{Al}\left\{\mathrm{OC}\left(\mathrm{CF}_{3}\right)_{3}\right\}_{4}\right]$ precursor $\left(\delta_{\mathrm{F}}:-75.70 \mathrm{ppm}, d_{2}-\mathrm{DCM}\right)$.

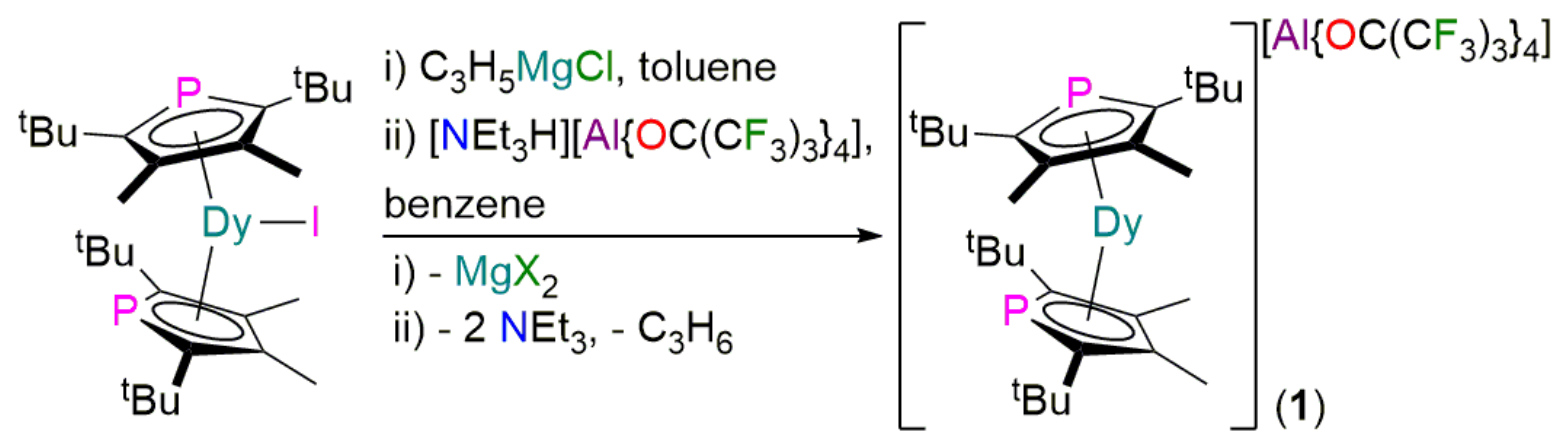

Scheme 1. Synthesis of 1.

\section{Structural characterisation}

The solid-state structure of $\mathbf{1}$ was determined by single crystal X-ray diffraction (Figure 1). The $\left[\mathrm{Dy}(\mathrm{Dtp})_{2}\right]^{+}$cation in 1 exhibits a bent geometry, with a $\mathrm{Dtp}_{\mathrm{cent}} \cdots \mathrm{Dy} \cdots \mathrm{Dtp} \mathrm{p}_{\mathrm{cent}}$ angle of $157.94(4)^{\circ}$ and 


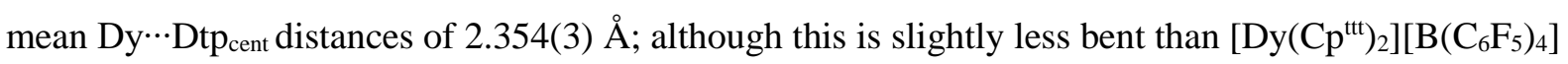
$\left(\mathrm{Cp}^{\mathrm{tt} t}{ }_{\text {cent }} \cdots \mathrm{Dy} \cdots \mathrm{Cp}^{\mathrm{ttt}}{ }_{\text {cent }}: 152.56(7)^{\circ}\right.$; Dy $\left.\cdots \mathrm{Cp}^{\mathrm{ttt}}{ }_{\text {cent }}: 2.316(3) \AA\right),{ }^{6}$ the incorporation of phosphorus in the rings has led to increased Dy-ligand distances. As expected from removal of an equatorial iodide, the $\mathrm{Dy}^{3+}$ centre in 1 has a larger Dtp $\mathrm{p}_{\mathrm{cent}} \cdots \mathrm{Dy} \cdots \mathrm{Dtp}_{\mathrm{cent}}$ angle and shorter Dy $\cdots$ Dtp $\mathrm{p}_{\text {cent }}$ distances than the

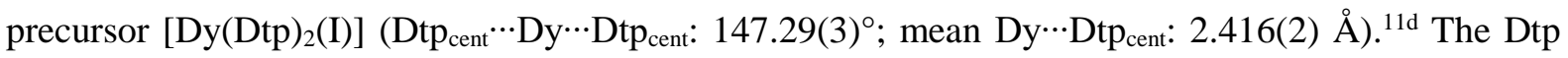
rings in $\mathbf{1}$ are staggered with respect to each other, with the phosphorus atoms at adjacent positions (mean Dy-P: 2.7931(11) $\AA$ ). Although an $\eta^{5}$-binding mode is adopted there is a significant variation in Dy-C $\mathrm{C}_{\mathrm{Dtp}}$ distances; range 2.570(3)-2.780(3) $\AA$, $c f$. $2.702(2)-2.778(2)$ for $\left[\mathrm{Dy}(\mathrm{Dtp})_{2}(\mathrm{I})\right] .{ }^{11 \mathrm{~d}}$ As previously seen for $\left[\mathrm{Dy}\left(\mathrm{Cp}^{\mathrm{ttt}}\right)_{2}\right]\left[\mathrm{B}\left(\mathrm{C}_{6} \mathrm{~F}_{5}\right)_{4}\right]$ (range Dy-C: $\left.2.560(4)-2.699(4) \AA\right),{ }^{6}$ the electron deficient $\mathrm{Dy}^{3+}$ centre in $\mathbf{1}$ forms additional stabilizing electrostatic contacts with ${ }^{\mathrm{B} u}$ groups, with two short Dy $\cdots \mathrm{C}(2.881(3)$ and 3.026(4) $\AA$ ) and two short Dy $\cdots \mathrm{H}(2.481$ and $2.541 \AA)$ distances. The metrical parameters of the $\left[\mathrm{Al}\left\{\mathrm{OC}\left(\mathrm{CF}_{3}\right)_{3}\right\}_{4}\right]^{-}$anions are unremarkable, and it does not show any interaction with the $\mathrm{Dy}^{3+}$ centre (shortest Dy $\cdots \mathrm{F}$ distance $>6.0 \AA$ ).
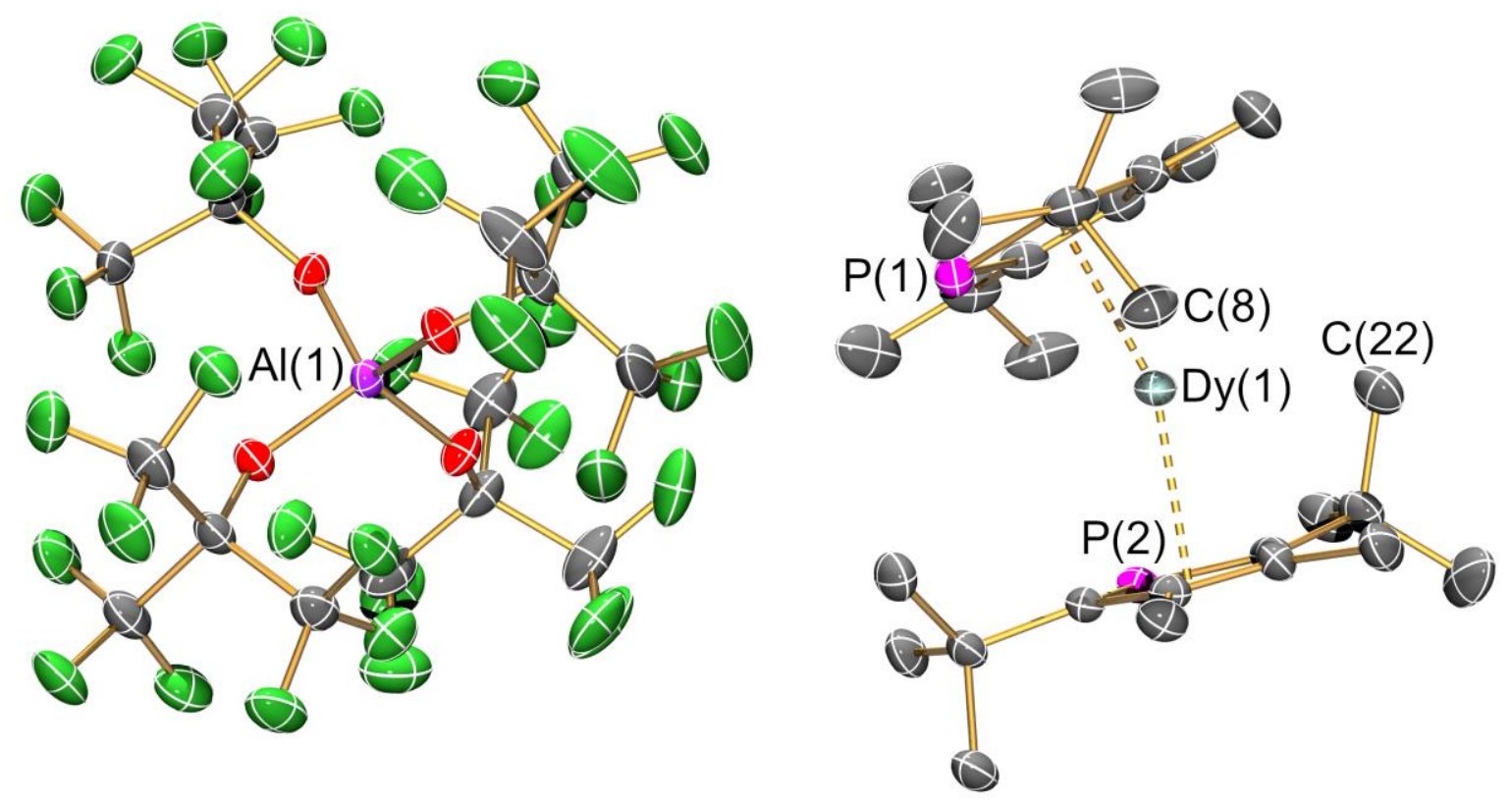

Figure 1. Molecular structure of $\left[\mathrm{Dy}(\mathrm{Dtp})_{2}\right]\left[\mathrm{Al}\left\{\mathrm{OC}\left(\mathrm{CF}_{3}\right)_{3}\right\}_{4}\right]$ (1) with selected atom labelling. Displacement ellipsoids set at 50\% probability level, solvent of crystallization (DCM) and hydrogen atoms are omitted for clarity. $\mathrm{C}$ atoms are grey, $\mathrm{O}$ atoms are red and $\mathrm{F}$ atoms are green. Selected bond 


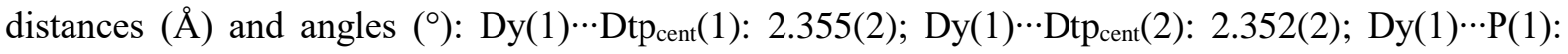
2.7981(8); Dy(1) $\cdots \mathrm{P}(2): 2.7880(8)$; range $\operatorname{Dy}(1) \cdots \mathrm{C}_{\mathrm{Dtp}}: 2.570(3)-2.780(3) ; \operatorname{Dy}(1) \cdots \mathrm{C}(8): 2.881(3)$; $\operatorname{Dy}(1) \cdots \mathrm{C}(22): 3.026(4) ; \operatorname{Dy}(1) \cdots \mathrm{H}(8 \mathrm{~A}): 2.481 ; \operatorname{Dy}(1) \cdots \mathrm{H}(22 \mathrm{~A}): 2.541 ; \operatorname{Dtp}_{\text {cent }}(1) \cdots \operatorname{Dy}(1) \cdots \operatorname{Dtp}_{\text {cent }}(2):$

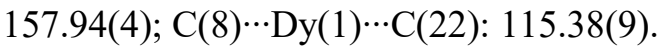

\section{Magnetism}

A polycrystalline sample of $\mathbf{1}$ suspended in eicosane was analysed by SQUID magnetometry to determine its magnetic properties. The magnetic susceptibility temperature product $\left(\chi_{M} T\right)$ of solid $\mathbf{1}$ at $300 \mathrm{~K}$ is $13.85 \mathrm{~cm}^{3} \mathrm{~K} \mathrm{~mol}^{-1}$ (ESI Figure $\mathrm{S} 8$ ); this is in accord with the free-ion Curie value of 14.17 $\mathrm{cm}^{3} \mathrm{~K} \mathrm{~mol}^{-1} 18$ and ab initio calculations $\left(13.66 \mathrm{~cm}^{3} \mathrm{~K} \mathrm{~mol}^{-1}\right.$, see below). A steady reduction in $\chi_{M} T$ with temperature for solid 1 was observed down to $25 \mathrm{~K}\left(12.28 \mathrm{~cm}^{3} \mathrm{~K} \mathrm{~mol}^{-1}\right)$, owing to thermal depopulation of excited crystal field (CF) states. A more severe drop in $\chi_{M} T$ was observed below $25 \mathrm{~K}$ due to the onset of magnetic blocking, which correlates with the temperature at which the zero-field cooled (ZFC) susceptibility has a plateau $\left(T_{\mathrm{B} 1}=25 \mathrm{~K}\right.$; ESI Figure S10). The non-traditional profiles of the field cooled (FC) and ZFC susceptibilities are a complicated function of the measurement protocol (temperature sweep rate, magnetic field strength and field sweep rate) as well as the intricate field and temperature dependence of magnetic relaxation in $\mathrm{Dy}^{3+} \mathrm{SMMs} ;{ }^{19}$ such traces have been explained by others. ${ }^{20}$ The most salient information from the FC/ZFC traces is the temperature at which the two datasets bifurcate: for 1, $T_{\text {irrev }}=54 \mathrm{~K}($ ESI Figure S11).

Slow relaxation of magnetisation for $\mathbf{1}$ was confirmed by the presence of out-of-phase maxima between 60 and $80 \mathrm{~K}$ in the zero-field AC susceptibility data (ESI Figure S12 and S13). The temperature dependence of the relaxation times obtained from these measurements were fitted to a generalised Debye model using CC-FIT2 ${ }^{21}$ (Figure 2), which allows the extraction of uncertainties in the magnetic relaxation times from the underlying distribution function. We observe an exponential relaxation process (Orbach mechanism; $\tau^{-1}=\tau_{0}^{-1} \exp \left[-U_{\text {eff }} / \mathrm{T}\right]$ ) above $50 \mathrm{~K}$, and extract an effective barrier to magnetisation reversal $U_{\text {eff }}=1,760(70) \mathrm{K}\left(1,220(50) \mathrm{cm}^{-1}\right)$, with $\tau_{0}=10^{-11.7(4)} \mathrm{s}\left(\mathrm{ca} .2 \times 10^{-12} \mathrm{~s}\right)$. The $U_{\text {eff }}$ value for $\mathbf{1}$ is identical to that previously seen for $\left[\mathrm{Dy}\left(\mathrm{Cp}^{\mathrm{ttt}}\right)_{2}\right]\left[\mathrm{B}\left(\mathrm{C}_{6} \mathrm{~F}_{5}\right)_{4}\right](1,760 \mathrm{~K}),{ }^{6}$ and smaller than the current record-holder $\left[\mathrm{Dy}\left(\mathrm{C}_{5}{ }^{\mathrm{i}} \mathrm{Pr}_{5}\right)\left(\mathrm{C}_{5} \mathrm{Me}_{5}\right)\right]\left[\mathrm{B}\left(\mathrm{C}_{6} \mathrm{~F}_{5}\right)_{4}\right](2,217 \mathrm{~K}){ }^{7 \mathrm{~b}}$ To obtain relaxation times at 
lower temperature, we performed magnetisation decay experiments and fitted the data with stretched exponentials (Figure S14 Table S3). Following a similar approach for obtaining uncertainties from ac data, ${ }^{21}$ we determined uncertainties from the magnetisation decay experiments based on the well-known distribution underlying the stretched exponential function (see ESI, Figure S14), ${ }^{22}$ this gives $\tau_{ \pm}=$ $\tau_{\mu} e^{ \pm \frac{1.64 \tan \left[\frac{\pi}{2}(1-\beta)\right]}{(1-\beta)^{0.141}}}$ at the $1 \sigma$ level, where $\beta$ is the stretch factor. Below $30 \mathrm{~K}$ we observe a power-law relaxation process (Raman-like mechanism; $\tau^{-1}=C \mathrm{~T}^{n}$ ) for $\mathbf{1}$, and this data is well-reproduced with $n=$ 1.1(3) and $C=10^{-3.5(3)} \mathrm{s}^{-1} \mathrm{~K}^{-n}\left(c a .3 \times 10^{-4} \mathrm{~s}^{-1} \mathrm{~K}^{-n}\right)$. The small $n$ value approaches that expected for the Direct relaxation process ${ }^{23}$ however as these data are collected in zero magnetic field this is not a plausible mechanism. Indeed all bis-cyclopentadienyl $\mathrm{Dy}^{3+}$ cations have relatively low Raman exponents of between 2 and 3 in the crystalline phase, ${ }^{6,7}$ and thus substitution of $\mathrm{C}$ for $\mathrm{P}$ in the first coordination sphere of $\mathbf{1}$ does not appear to grossly alter this characteristic; however, it cannot be ascertained if the even lower exponent of 1.1(3) here is due to the effect of the ring substitution or to the different counter ion ( $\left[\mathrm{Al}\left\{\mathrm{OC}\left(\mathrm{CF}_{3}\right)_{3}\right\}_{4}\right]^{-} c f$. $\left[\mathrm{B}\left(\mathrm{C}_{6} \mathrm{~F}_{5}\right)_{4}\right]^{-}$for all dysprosocenium SMMs to date). While we cannot measure the relaxation dynamics between 30 and $64 \mathrm{~K}$, extrapolation of the Orbach and Raman regions suggest that they intersect at $52 \mathrm{~K}$ which coincides with the bifurcation of FC/ZFC plots $\left(T_{\text {irrev }}=54 \mathrm{~K}\right)$ : such a sharp intersection between the Raman and Orbach regions was observed for $\left[\mathrm{Dy}\left(\mathrm{Cp}^{\mathrm{ttt}}\right)_{2}\right]\left[\mathrm{B}\left(\mathrm{C}_{6} \mathrm{~F}_{5}\right)_{4}\right]$, as was the coincidence of the intersection temperature and $T_{\text {irrev. }}{ }^{6}$ Using magnetisation decays we have been able to directly measure the $100 \mathrm{~s}$ blocking temperature as $T_{\mathrm{B} 2}=23$ K. Overall, magnetic relaxation is around $10-100$ times faster in the range $2-100 \mathrm{~K}$ for $\mathbf{1}$ than for $\left[\mathrm{Dy}\left(\mathrm{Cp}^{\mathrm{tt}}\right)_{2}\right]\left[\mathrm{B}\left(\mathrm{C}_{6} \mathrm{~F}_{5}\right)_{4}\right]($ ESI Figure S15). 


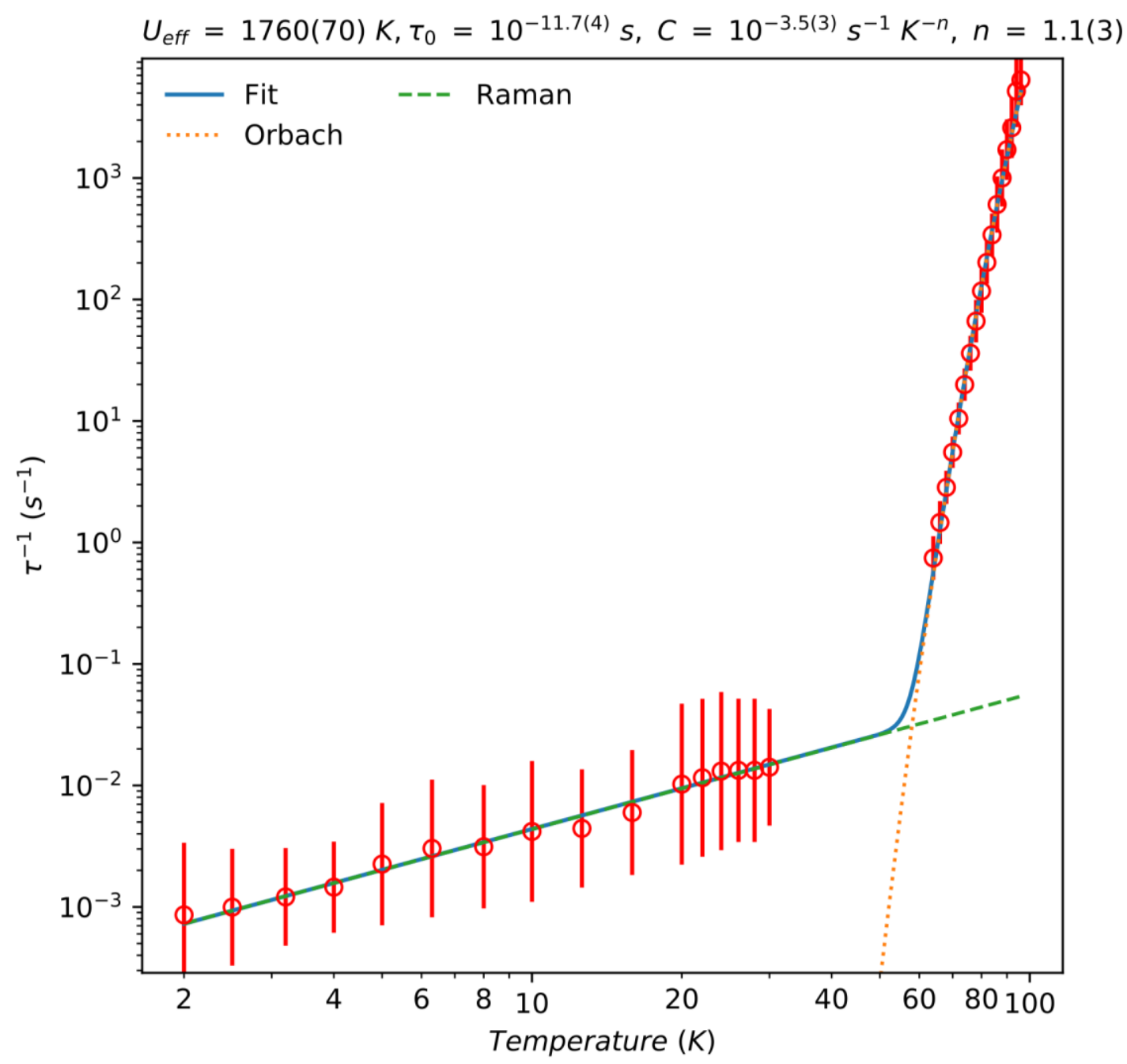

Figure 2. Temperature dependence of the magnetic relaxation rate of $\mathbf{1}$. Red circles are the relaxation rates extracted from ac susceptibility data (high temperature) and dc magnetisation decay data (low temperature); solid red lines are error bars from the distributions of relaxation times (see ESI). ${ }^{21}$ The solid blue line is given by $\tau^{-1}=\tau_{0}^{-1} \exp \left[-U_{\mathrm{eff}} / T\right]+C \mathrm{~T}^{n}$, the dashed green line is given by $\tau^{-1}=\tau_{0}^{-1} \exp [-$ $\left.U_{\text {eff }} / T\right]$ and the dotted orange line is given by $\tau^{-1}=C \mathrm{~T}^{n}$ with $U_{\text {eff }}=1,760(70) \mathrm{K}, \tau_{0}=10^{-11.7(4)} \mathrm{s}, C=10^{-}$ 3.5(3) $\mathrm{s}^{-1} \mathrm{~K}^{-n}$ and $n=1.1(3)$.

Solid 1 shows open, but comparatively waist-restricted, magnetic hysteresis loops up to $T_{\mathrm{H}}=$ $48 \mathrm{~K}$ (Figure 3), using a sweep rate of $c a .20 \mathrm{Oe} / \mathrm{s}$ around the important zero-field region where quantum tunnelling of the magnetisation (QTM) dominates for Ln SMMs. ${ }^{4}$ The value of $T_{\mathrm{H}}$ for $\mathbf{1}$ is lower than the majority of isolated dysprosocenium cations reported to date, which have shown $T_{\mathrm{H}}$ values of $60-$ $80 \mathrm{~K},{ }^{6,7}$ except for one example, $\left[\mathrm{Dy}\left(\mathrm{C}_{5}{ }^{\mathrm{i}} \mathrm{Pr}_{4} \mathrm{H}\right)_{2}\right]\left[\mathrm{B}\left(\mathrm{C}_{6} \mathrm{~F}_{5}\right)\right]\left(T_{\mathrm{H}}=32 \mathrm{~K}\right),{ }^{7 \mathrm{a}}$ which contains ring $\mathrm{C}-\mathrm{H}$ 
protons that have been postulated to enhance magnetic relaxation mechanisms. ${ }^{6}$ Despite the lack of ring protons in $\mathbf{1}$, it shows open hysteresis to a maximum temperature that is $12 \mathrm{~K}$ lower than that previously seen for $\left[\mathrm{Dy}\left(\mathrm{Cp}^{\mathrm{ttt}}\right)_{2}\right]\left[\mathrm{B}\left(\mathrm{C}_{6} \mathrm{~F}_{5}\right)_{4}\right]\left(T_{\mathrm{H}}=60 \mathrm{~K}\right) .^{6}$
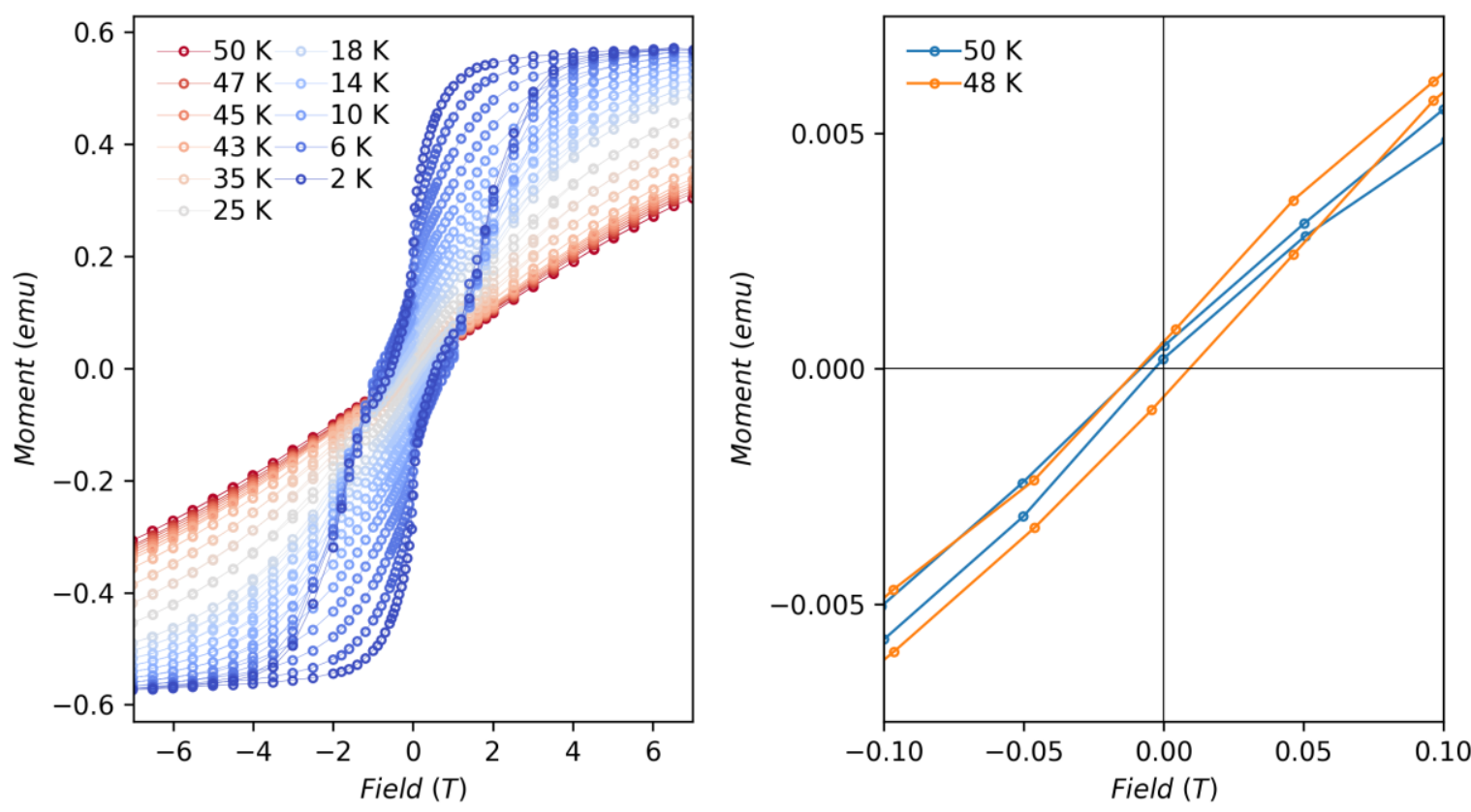

Figure 3. Magnetic hysteresis of solid 1, measured with a mean field sweep rate of 21(9) Oe $\mathrm{s}^{-1}$ for $|\mathrm{H}|$ $<10 \mathrm{kOe}, 49(12) \mathrm{Oe} \mathrm{s}^{-1}$ for $10<|\mathrm{H}|<20 \mathrm{kOe}$, and 88(17) Oe s${ }^{-1}$ for $20<|\mathrm{H}|<70 \mathrm{kOe}$. Hysteresis loops recorded from $2-18 \mathrm{~K}$ in $2 \mathrm{~K}$ steps, from $20-40 \mathrm{~K}$ in $5 \mathrm{~K}$ steps and from $43-50 \mathrm{~K}$ in $1 \mathrm{~K}$ steps.

\section{Ab initio calculations}

First principles complete active space self-consistent field spin-orbit (CASSCF-SO) calculations were performed on the crystal structure of the cation in $\mathbf{1}$ to complement experimental data and to probe magnetic relaxation mechanisms (ESI Table S4). As expected for a strongly axial CF, we observe an easy-axis ground Kramers doublet corresponding to the $m_{J}= \pm 15 / 2 \mathrm{CF}$ state, where the first five excited states are also easy-axis like and collinear with the ground doublet; the five excited states are dominated by the $m_{J}= \pm 13 / 2, \pm 11 / 2, \pm 9 / 2, \pm 7 / 2$ and $\pm 5 / 2$, respectively. The $g$-values for the sixth excited Kramers doublet are highly rhombic, indicating a substantially mixed $m_{J}$ composition, and thus magnetic relaxation by the Orbach process is likely to occur via this state (ca. $1,716 \mathrm{~K}$, which compares 
reasonably well with the experimental $\left.U_{\text {eff }}=1,760(70) \mathrm{K}\right)$. To gain more insight into the relaxation dynamics, we have calculated the spin dynamics using our previously described ab initio method; ${ }^{6}$ briefly, this entails: i) optimisation of molecular geometry and determination of vibrational modes with DFT, ii) calculation of spin-phonon coupling with CASSCF-SO, iii) simulation of magnetic relaxation via a semi-classical master equation (see ESI for details). We find excellent agreement with the experimental data in the high-temperature region corresponding to Orbach relaxation (Figure 4a); note that relaxation via two-phonon Raman processes at low temperatures are not accounted for in these calculations. Examining the calculated relaxation rates carefully, we observe that relaxation shows two different exponential processes in different temperature regimes (ESI Figure S16), and that this has a slight dependence upon the choice of phonon linewidth (ESI Table S6). We find that magnetic relaxation follows an Orbach process over an effective barrier of $c a .1,500-1,700 \mathrm{~K}$ following the pathway shown in Figure 4b, but at temperatures less than $c a .50 \mathrm{~K}$ the effective barrier is reduced to ca. 660 - $960 \mathrm{~K}$ (ESI Table S6, Figures S16 and S17). The experimental data for 1 show only one Orbach process with $U_{\text {eff }}=1,760(70) \mathrm{K}$ down to $64 \mathrm{~K}$ and the onset of Raman relaxation below $30 \mathrm{~K}$; thus, a potential crossover to a smaller $U_{\text {eff }}$ regime may occur between 64 and $30 \mathrm{~K}$, however we cannot probe these timescales with our instrumentation.

Decomposing the relaxation rates for the large $U_{\text {eff }}$ process, the first step in magnetic relaxation is delicately balanced between the $| \pm 15 / 2\rangle$ to $| \pm 13 / 2\rangle$ and the $| \pm 15 / 2\rangle$ to $| \pm 11 / 2\rangle$ transitions: lower temperatures and larger phonon linewidths favour the former, whilst higher temperatures and smaller phonon linewidths favour the latter (Figure $4 \mathrm{~b} c f$. ESI Figure S18). The $| \pm 15 / 2\rangle$ to $| \pm 13 / 2\rangle$ transition is mostly driven by mode 61; which is an in-plane slippage of the rings (ESI Figure S19), whereas the $| \pm 15 / 2\rangle$ to $| \pm 11 / 2\rangle$ transition is driven by mode 77 , which involves axial distortions of the $\mathrm{Dy}^{3+}$ centre via the carbon atoms of the Dtp rings (ESI Figure S20). 

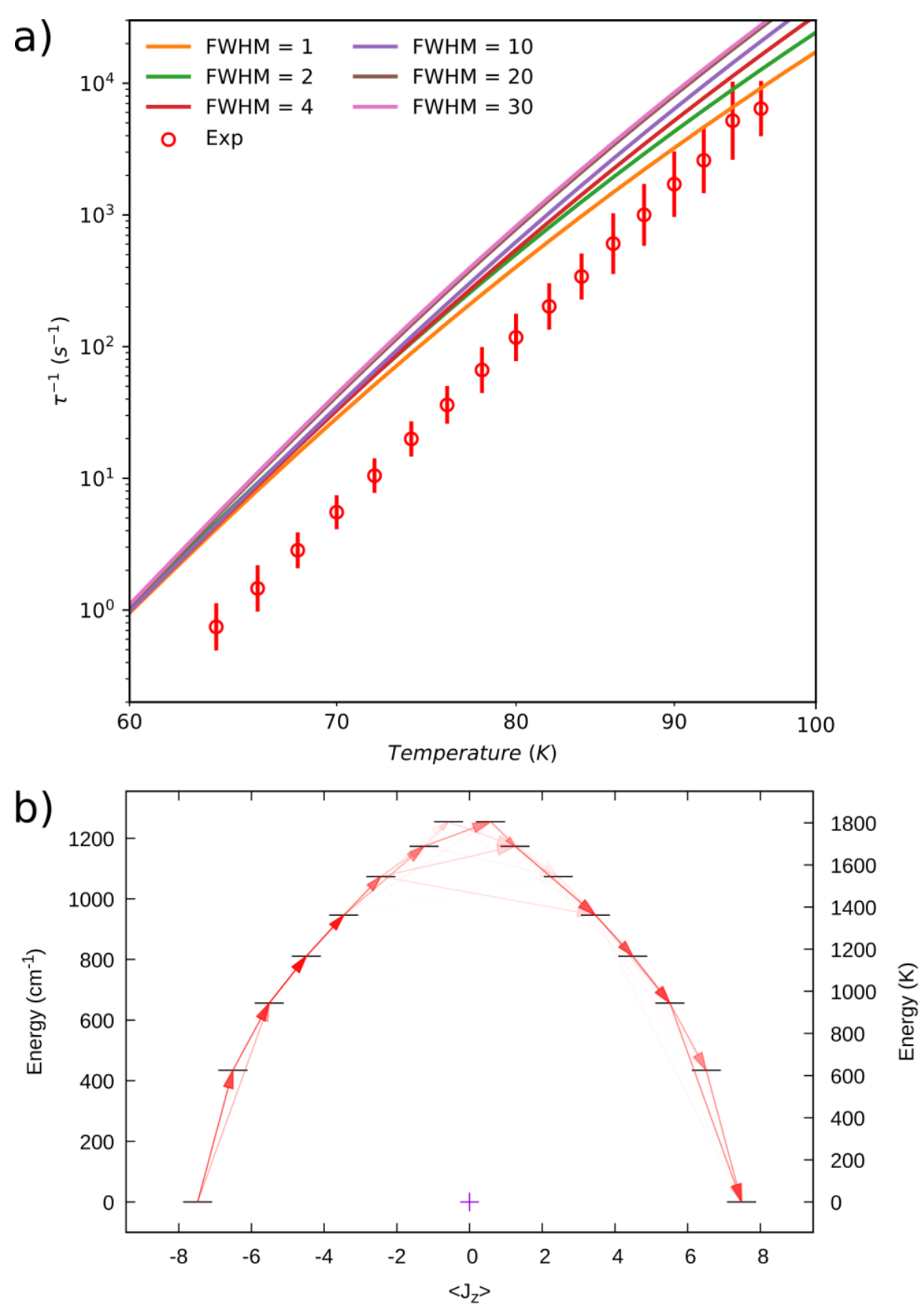

Figure 4. (a) Ab initio calculated magnetic relaxation rates for $\mathbf{1}$ (lines) compared with the experimental data (points). (b) Energy barrier to magnetic relaxation for 1, calculated at $100 \mathrm{~K}$ and using FWHM = $10 \mathrm{~cm}^{-1}$. Electronic states from CASSCF-SO calculations, decomposed in the $J=15 / 2$ basis. The opacity of the arrows is proportional to the single-phonon transition probability normalized from each departing state and commencing with unit population in $|-15 / 2\rangle$; only relaxation pathways towards $|+15 / 2\rangle$ are shown. $\left\langle J_{z}\right\rangle$ is the expectation value of the $J_{z}$ operator along the quantization axis. 
Experimentally we observe that 1 relaxes faster than $\left[\mathrm{Dy}\left(\mathrm{Cp}^{\mathrm{ttt}}\right)_{2}\right]\left[\mathrm{B}\left(\mathrm{C}_{6} \mathrm{~F}_{5}\right)_{4}\right]$ in the Orbach regime (ESI Figure S15), and this is also borne out in comparable simulations (ESI Figure S21). However, between 50 and $300 \mathrm{~K}$ the escape rate of the $| \pm 15 / 2\rangle$ state in $\left[\mathrm{Dy}\left(\mathrm{Cp}^{\mathrm{ttt}}\right)_{2}\right]\left[\mathrm{B}\left(\mathrm{C}_{6} \mathrm{~F}_{5}\right)_{4}\right]$ is approximately an order of magnitude faster than for 1 (ESI Table S7), owing to the much faster $| \pm 15 / 2\rangle$ to $| \pm 13 / 2\rangle$ transitions in $\left[\mathrm{Dy}\left(\mathrm{Cp}^{\mathrm{ttt}}\right)_{2}\right]\left[\mathrm{B}\left(\mathrm{C}_{6} \mathrm{~F}_{5}\right)_{4}\right]$ (ESI Table S8), seemingly in contradiction with the overall calculated relaxation rates (ESI Figure S21). However, we note that all electronic states in $\mathbf{1}$ are compressed in energy $c f$. $\left[\mathrm{Dy}\left(\mathrm{Cp}^{\mathrm{ttt}}\right)_{2}\right]\left[\mathrm{B}\left(\mathrm{C}_{6} \mathrm{~F}_{5}\right)_{4}\right]$ (ESI Figure S22) due to a weaker crystal field, and that this brings the subsequent steps in relaxation $\left(| \pm 13 / 2\rangle\right.$ to $| \pm 11 / 2\rangle$ at $224 \mathrm{~cm}^{-1},| \pm 11 / 2\rangle$ to $| \pm 9 / 2\rangle$ at 150 $\mathrm{cm}^{-1}$ and $| \pm 9 / 2\rangle$ to $| \pm 7 / 2\rangle$ at $130 \mathrm{~cm}^{-1}$ ) into resonance with vibrational modes with significant spinphonon coupling (ESI Figures S23 and S24; ESI Table S9). These excitations in [Dy $\left.\left(\mathrm{Cp}^{\mathrm{ttt}}\right)_{2}\right]\left[\mathrm{B}\left(\mathrm{C}_{6} \mathrm{~F}_{5}\right)_{4}\right]$ are 268, 173 and $158 \mathrm{~cm}^{-1},{ }^{6}$ and the relevant vibrational modes are further off-resonance (ESI Figures S23 and S24). Therefore, although chemical alteration of the aromatic rings has made the initial steps in magnetic relaxation slower, confirming our hypothesis, magnetic relaxation in the Orbach regime in $\mathbf{1}$ is more efficient than for $\left[\mathrm{Dy}\left(\mathrm{Cp}^{\mathrm{ttt}}\right)_{2}\right]\left[\mathrm{B}\left(\mathrm{C}_{6} \mathrm{~F}_{5}\right)_{4}\right]$ due to faster relaxation in the upper energy states of the manifold (ESI Table S9).

\section{Conclusion}

In conclusion, we have shown that isolated bis-monophospholyl dysprosium cations can show relatively high $U_{\text {eff }}$ and $T_{\max }$ values, in common with the cationic bis-cyclopentadienyl dysprosium family. Despite the lack of ring protons in $\left[\mathrm{Dy}(\mathrm{Dtp})_{2}\right]\left[\mathrm{Al}\left\{\mathrm{OC}\left(\mathrm{CF}_{3}\right)_{3}\right\}_{4}\right]$, and its effective magnetisation barrier being identical to that of $\left[\mathrm{Dy}\left(\mathrm{Cp}^{\mathrm{ttt}}\right)_{2}\right]\left[\mathrm{B}\left(\mathrm{C}_{6} \mathrm{~F}_{5}\right)_{4}\right],{ }^{6}$ the maximum hysteresis temperature of $\left[\mathrm{Dy}(\mathrm{Dtp})_{2}\right]\left[\mathrm{Al}\left\{\mathrm{OC}\left(\mathrm{CF}_{3}\right)_{3}\right\}_{4}\right]$ is $12 \mathrm{~K}$ lower than this literature example. Ab initio calculations indicate that the replacement of aromatic $\mathrm{C}_{5}$ rings with $\mathrm{C}_{4} \mathrm{P}$ analogues has slowed down transitions out of the ground $| \pm 15 / 2\rangle$ doublet as intended. However, smaller energy gaps between excited states that are onresonance with a series of vibrational modes has rendered relaxation more efficient overall in $\left[\mathrm{Dy}(\mathrm{Dtp})_{2}\right]\left[\mathrm{Al}\left\{\mathrm{OC}\left(\mathrm{CF}_{3}\right)_{3}\right\}_{4}\right]$. Therefore, as with the bis-cyclopentadienyl dysprosium cation family, ${ }^{6,7}$ the efficacy of magnetic relaxation processes in isolated bis-phospholyl dysprosium cations are also not 
trivially predictable. This is crucial new information for the future design of lanthanide SMMs with higher magnetic blocking temperatures.

\section{Experimental Section}

All manipulations were conducted under argon with the strict exclusion of oxygen and water by using Schlenk line and glove box techniques. Benzene was dried by refluxing over potassium and was stored over a potassium mirror. Chlorobenzene was dried over $\mathrm{CaH}_{2}$ and was stored over $4 \AA$ molecular sieves. All solvents were degassed before use. For NMR spectroscopy $\mathrm{C}_{6} \mathrm{D}_{5} \mathrm{Cl}$ was dried by refluxing over $\mathrm{CaH}_{2}$, and was vacuum transferred and degassed by three freeze-pump-thaw cycles before use. $\left[\mathrm{Dy}(\mathrm{Dtp})_{2}(\mathrm{I})\right]^{11 \mathrm{~d}}$ and $\mathrm{Li}\left[\mathrm{Al}\left\{\mathrm{OC}\left(\mathrm{CF}_{3}\right)_{3}\right\}_{4}\right]^{12}$ were prepared according to literature methods, and $\mathrm{DyI}_{3}$ (Alfa Aesar) and $\mathrm{C}_{3} \mathrm{H}_{5} \mathrm{MgCl}$ (Sigma-Aldrich) were purchased and were used as received. ${ }^{1} \mathrm{H}$ (400 MHz), ${ }^{13} \mathrm{C}(100 \mathrm{MHz}$ and $125 \mathrm{MHz}),{ }^{31} \mathrm{P}(162 \mathrm{MHz})$ and ${ }^{19} \mathrm{~F}(376 \mathrm{MHz}) \mathrm{NMR}$ spectra were obtained on an Avance III $400 \mathrm{MHz}$ or $500 \mathrm{MHz}$ spectrometer at $298 \mathrm{~K}$. These were referenced to the solvent used, or to external TMS $\left({ }^{1} \mathrm{H},{ }^{13} \mathrm{C}\right), \mathrm{H}_{3} \mathrm{PO}_{4}\left({ }^{31} \mathrm{P}\right)$ or $\mathrm{C}_{7} \mathrm{H}_{5} \mathrm{~F}_{3} / \mathrm{CDCl}_{3}\left({ }^{19} \mathrm{~F}\right)$. FTIR spectra were recorded as microcrystalline powders using a Bruker Tensor 27 ATR-Fourier Transform infrared (ATRFTIR) spectrometer. Elemental analysis was carried out by Mr Martin Jennings and Mrs Anne Davies at the Microanalytical service, School of Chemistry, the University of Manchester.

$\left[\mathbf{D y}(\mathbf{D t p})_{2}\right]\left[\mathbf{A l}\left\{\mathbf{O C}\left(\mathbf{C F}_{3}\right)_{3}\right\}_{4}\right](\mathbf{1})$. A slurry of $\operatorname{DyI}_{3}(0.4997 \mathrm{~g}, 0.92 \mathrm{mmol})$ and DtpK $(0.5311 \mathrm{~g}$, $2.02 \mathrm{mmol})$ in toluene $(20 \mathrm{ml})$ was heated under reflux for $48 \mathrm{~h}$. The resultant yellow reaction mixture was allowed to cool to room temperature and filtered; the remaining solids were washed with toluene (20 ml). A solution of $\left(\mathrm{C}_{3} \mathrm{H}_{5}\right) \mathrm{MgCl}$ in THF $(2.0 \mathrm{M}, 0.7 \mathrm{ml}, 1.4 \mathrm{mmol})$ was added to the yellow filtrate and stirred for $1.5 \mathrm{~h}$ to give an orange reaction mixture. The solvents were removed in vacuo to give a sticky orange solid, which was triturated with a mixture of $n$-hexane and dioxane (20:1, $30 \mathrm{ml})$. The product was extracted into $n$-hexane $(15 \mathrm{ml})$, filtered, and solvents were removed in vacuo to give an orange foam $\left.(0.4100 \mathrm{~g}, 0.63 \mathrm{mmol}, 69 \% \text { crude yield of the putative "[Dy(Dtp })_{2}\left(\mathrm{C}_{3} \mathrm{H}_{5}\right)\right]$ "). $\left[\mathrm{NEt}_{3} \mathrm{H}\right]\left[\mathrm{Al}\left\{\mathrm{OC}\left(\mathrm{CF}_{3}\right)_{3}\right\}_{4}\right](0.6741 \mathrm{~g}, 0.63 \mathrm{mmol})$ and benzene $(15 \mathrm{ml})$ were added and the yelloworange reaction mixture was stirred overnight. Volatiles from the resultant orange oil and yellow solution were removed in vacuo. The yellow foam obtained was washed with $n$-hexane $(20 \mathrm{ml})$ and 
benzene $(15 \mathrm{ml})$, and the residual solvent was removed in vacuo to give a yellow foam. The product was extracted into chlorobenzene $(15 \mathrm{ml})$, filtered and reduced in volume to $10 \mathrm{ml}$, and layered with $n$ hexane (35 ml). After standing for 3 days at room temperature large yellow crystals were obtained; these were washed with $n$-hexane dried to give $1\left(0.3764 \mathrm{~g}, 26 \%\right.$ yield based on $\left.\mathrm{DyI}_{3}\right)$. Anal. Calcd (\%) for $\mathrm{C}_{44} \mathrm{H}_{48} \mathrm{AlDyF}_{36} \mathrm{O}_{4} \mathrm{P}_{2}: \mathrm{C}, 33.51 ; \mathrm{H}, 3.07$. Found: $\mathrm{C}, 30.86 ; \mathrm{H}, 2.78$. Elemental analysis results consistently gave lower carbon values than predicted, which we attribute to carbide formation from incomplete combustion. However, all other analytical data obtained are consistent with the bulk purity of 1. $\chi T$ product $=14.28 \mathrm{~cm}^{3} \mathrm{~mol}^{-1} \mathrm{~K}$ (Evans method). ${ }^{19} \mathrm{~F}$ NMR $\left(\mathrm{C}_{6} \mathrm{D}_{5} \mathrm{Cl}\right): \delta=-90.50\left(\mathrm{br}, v^{1 / 2}=300\right.$ $\mathrm{Hz}$ ). The paramagnetism of $\mathbf{1}$ precluded assignment of its ${ }^{1} \mathrm{H},{ }^{13} \mathrm{C}$ and ${ }^{31} \mathrm{P}$ NMR spectra. FTIR (ATR, microcrystalline): $\tilde{v}=2964$ (w, br), $1472(\mathrm{w}), 1397(\mathrm{w}), 1352(\mathrm{w}), 1297(\mathrm{~m}), 1274(\mathrm{~m}), 1239(\mathrm{~m}), 1210$ (st), $1165(\mathrm{~m}), 1022(\mathrm{w}), 970$ (st), 832 (w, br), $726(\mathrm{st}), 660(\mathrm{w}), 624(\mathrm{w}), 560(\mathrm{w}), 536(\mathrm{~m}), 442(\mathrm{~m})$ $\mathrm{cm}^{-1}$.

$\left[\mathbf{N E t}_{3} \mathbf{H}\right]\left[\mathrm{Al}\left\{\mathbf{O C}\left(\mathbf{C F}_{3}\right)_{3}\right\}_{4}\right]$. A slurry of $\mathrm{Li}\left[\mathrm{Al}\left\{\mathrm{OC}\left(\mathrm{CF}_{3}\right)_{3}\right\}_{4}\right](9.7404 \mathrm{~g}, 10.0 \mathrm{mmol})$ and $\mathrm{NEt}_{3} \mathrm{HCl}$ $(1.3765 \mathrm{~g}, 10.0 \mathrm{mmol})$ in DCM $(175 \mathrm{ml})$ was stirred overnight. The resultant colourless suspension was filtered and the solvent was removed from the filtrate in vacuo to give a white powder $(7.3038 \mathrm{~g}, 68 \%)$. This was used without further purification; on one occasion the product was recrystallized from a saturated DCM solution stored overnight at $-35{ }^{\circ} \mathrm{C}$ and the solid-state structure was determined by single crystal XRD (see ESI). Anal. Calcd (\%) for $\mathrm{C}_{22} \mathrm{H}_{16} \mathrm{AlF}_{36} \mathrm{~N}$ : C, 24.71; H, 1.51; N, 1.31. Found: $24.71 ; \mathrm{H}, 1.47 ; \mathrm{N}, 1.46 .{ }^{1} \mathrm{H}$ NMR $\left(\mathrm{CD}_{2} \mathrm{Cl}_{2}\right): \delta=1.44\left(\mathrm{t}, J_{\mathrm{HH}}=7.3 \mathrm{~Hz}, 9 \mathrm{H}, \mathrm{NCH}_{2} \mathrm{CH}_{3}\right), 3.3\left(\mathrm{q}, J_{\mathrm{HH}}=7.3\right.$ $\left.\mathrm{Hz}, 6 \mathrm{H}, \mathrm{NCH}_{2} \mathrm{CH}_{3}\right), 4.92\left(\mathrm{t}, J_{\mathrm{NH}}=54 \mathrm{~Hz}, 1 \mathrm{H}, \mathrm{NH}\right) .{ }^{13} \mathrm{C} \mathrm{NMR}\left(\mathrm{CD}_{2} \mathrm{Cl}_{2}\right): \delta=9.45\left(\mathrm{~m}, \mathrm{NCH}_{2} \mathrm{CH}_{3}\right), 49.04$ $\left(\mathrm{NCH}_{2} \mathrm{CH}_{3}\right), 78.75$ (br. s, $\left.\mathrm{OC}\left(\mathrm{CF}_{3}\right)_{2}\right), 121.22$ (q, $\left.J_{\mathrm{CF}}=293 \mathrm{~Hz}\right) .{ }^{19} \mathrm{~F} \mathrm{NMR}\left(\mathrm{CD}_{2} \mathrm{Cl}_{2}\right): \delta=-75.70$. FTIR (ATR, microcrystalline): $\tilde{v}=3252$ (w), 2986 (w, br), 1746 (w), 1397 (w), 1353 (w), 1271 (s), 1240 (st), 1200 (m), 1024 (w), 967 (st), 833 (w), 797 (w), 756 (w), 725 (st, s), 561 (m), $536(\mathrm{~m}), 439$ (m) cm-

\section{Acknowledgements}

We thank the UK Engineering and Physical Sciences Research Council (EPSRC) (EP/R002605X/1 for P.E., EP/P002560/1 for D.R. and EP/K039547/1 for a single crystal X-ray diffractometer), and N.F.C. thanks the University of Manchester for a Presidential Fellowship and the 
Royal Society for a University Research Fellowship. We acknowledge the EPSRC UK National Electron Paramagnetic Resonance Service for access to the SQUID magnetometer, and the University of Manchester for access to the Computational Shared Facility. Research data files supporting this publication are available from Mendeley Data at DOI:10.17632/m4ssv5mxrz.1. 


\section{References}

1. D. Gatteschi, R. Sessoli, J. Villain, Molecular Nanomagnets, Oxford University Press, 2006.

2. N. Ishikawa, M. Sugita, T. Ishikawa, S. Koshihara, Y. Kaizu, J. Am. Chem. Soc., 2003, 125, 8694.

3. J. D. Rinehart, J. R. Long, Chem. Sci., 2011, 2, 2078.

4. R. A. Layfield, M. Murugesu, Lanthanides and Actinides in Molecular Magnetism, Wiley-VCH, 2015.

5. Y.-S. Ding, N. F. Chilton, R. E. P. Winpenny, Y.-Z. Zheng, Angew. Chem. Int. Ed., 2016, 55, 16071.

6. C. A. P. Goodwin, F. Ortu, D. Reta, N. F. Chilton, D. P. Mills, Nature, 2017, 548, 439.

7. (a) K. R. McClain, C. A. Gould, K. Chakarawet, S. J. Teat, T. J. Groshens, J. R. Long, B. G. Harvey, Chem. Sci., 2018, 9, 8492; (b) F.-S. Guo, B. M. Day, Y.-C. Chen, M.-L. Tong, A. Mansikkamäki, R. A. Layfield, Science, 2018, 362, 1400; (c) C. A. Gould, K. R. McClain, J. Yu, T. J. Groshens, F. Furche, J. R. Long, B. G. Harvey, J. Am. Chem. Soc., 2019, 141, 12967.

8. F.-S. Guo, A. K. Bar, R. A. Layfield, Chem. Rev., 2019, 119, 8479.

9. K. Kotrle, R. Herchel, Inorg. Chem., 2019, 58, 14046.

10. (a) F. Nief, Coord. Chem. Rev., 1998, 178-180, 13; (b) F. Nief, Eur. J. Inorg. Chem., 2001, 891; (c) P. Le Floch, Coord. Chem. Rev., 2006, 250, 627.

11. (a) F. Nief, D. Turcitu, L. Ricard, Chem. Commun., 2002, 1646; (b) F. Nief, D. Turcitu, L. Ricard, Chem. Eur. J., 2003, 9, 4916; (c) F. Jaroschik, F. Nief, X.-F. Le Goff, L. Ricard, Organometallics, 2007, 26, 3552; (d) F. Jaroschik, F. Nief, X.-F. Le Goff, Polyhedron, 2009, 28, 2744; (e) L. Jacquot, M. Xémard, C. Clavaguéra, G. Nocton, Organometallics, 2014, 33, 4100; (f) F. Jaroschik, A. Momin, A. Martinez, D. Harakat, L. Ricard, X.-F. Le Goff, G. Nocton, Organometallics, 2016, 35, 2032.

12. I. Krossing, Chem. Eur. J., 2001, 7, 490.

13. D. Uraguchi, N. Kinoshita, T. Kizu, T. Ooi, J. Am. Chem. Soc., 2015, 137, 13768.

14. W. J. Evans, C. A. Seibel, J. W. Ziller, J. Am. Chem. Soc., 1998, 120, 6745.

15. I. Krossing, I. Raabe, Angew. Chem. Int. Ed., 2004, 43, 2066.

16. (a) C. A. P. Goodwin, D. Reta, F. Ortu, N. F. Chilton, D. P. Mills, J. Am. Chem. Soc., 2017, 139, 18714; (b) C. A. P. Goodwin, D. Reta, F. Ortu, J. Liu, N. F. Chilton, D. P. Mills, Chem. Commun., 
2018, 54, 9182; (c) J. Liu, D. Reta, J. Cleghorn, Y. X. Yeoh, F. Ortu, C. A. P. Goodwin, N. F. Chilton, D. P. Mills, Chem. Eur. J., 2019, 25, 7749.

17. J. B. Lambert, L. Lin, S. Keinan, Org. Biomol. Chem., 2003, 1, 2559.

18. D. A. Atwood, The Rare Earth Elements: Fundamentals and Applications, John Wiley and Sons Ltd., 2012.

19. Y.-S. Ding, K.-X. Yu, D. Reta, F. Ortu, R. E. P. Winpenny, Y.-Z. Zheng, N. F. Chilton, Nature Commun., 2018, 9, 3134.

20. J.-L. Liu, Y.-C. Chen, M.-L. Tong, Chem. Soc. Rev., 2018, 47, 2431.

21. D. Reta, N. F. Chilton, Phys. Chem. Chem. Phys. 2019, DOI:10.1039/C9CP04301B.

22. D. C. Johnston, Phys. Rev. B, 2006, 74, 184430.

23. A. Abragam, B. Bleaney, Electron Paramagnetic Resonance of Transition Ions, Clarendon Press, Oxford, 1970. 